\title{
Expanding standards
}

\author{
NASA scientist Drew Shindell teamed up with experts in health, agriculture and economics to \\ investigate the potential impacts of imposing tight vehicle-emission standards in developing countries.
}

What was the impetus for this project and what was the main objective of the work at the beginning of the project? The project was borne out of a meeting I had in 2008 with the California Air Resources Board, which is the body responsible for maintaining the state of California's air quality. They had been working on emissions regulations in California and had experts looking at local climate impacts, but no one was looking at the global impacts of implementing state regulations, such as vehicle-emission standards. Following on from the meeting, we did some analyses to explore the implications of imposing Californian vehicle-emission regulations worldwide, but the more we thought about it the more we realized that was a very artificial situation. So instead, we decided to look at what has happened globally in the past, which is that most developing countries tend to adopt European standards. We chose the developing countries that would have the most institutional and financial capacity to implement those standards in reality, and they became the focus of our analysis. In Latin America, Brazil had the capacity for the strictest standards, for example, but in Africa, we assumed that most countries would be able to adopt measures only modestly more stringent than those already in place.
How did you go about finding suitable collaborators?

At first I didn't make much headway in getting experts from different fields involved. But then I became involved in an initiative by the United Nations Environment Program and the World Meteorological Organization to look at the impacts of reducing black carbon and tropospheric ozone production on the rate of climate change. On that project, I got to know experts in health and agriculture, who then became involved with this interdisciplinary research project to look at vehicle-emission standards. Once they were on board, I had much better luck opting in other experts, such as an economist.

\section{Did any difficulties arise in working} with a team of experts with different research backgrounds and perspectives? I discovered that we were speaking a different language when it came to measurements and units. On one occasion, we had to re-run a whole set of scenarios because of a mismatch in the units used by people measuring the same thing but with different expertise. In another case, we had two physical scientists on the team exchanging e-mails in which they were discussing the variability of AOT. It wasn't until the team's economist asked what AOT stood for that we realized we were actually talking about two different

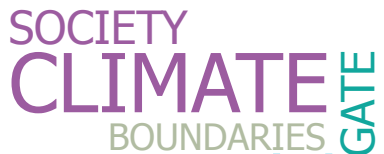

ANALYSISIMPOSING UI
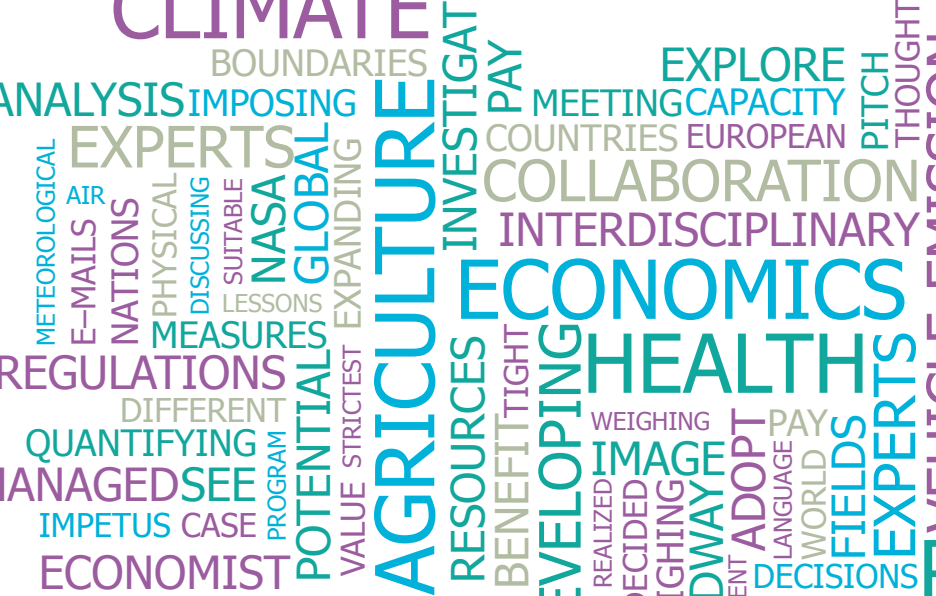

蒠

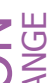
MISMATCH ASSUMED RRESEARCH תREST $\sum$ INTERDISCIPLINARY $₹$ POPL

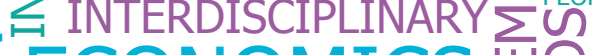

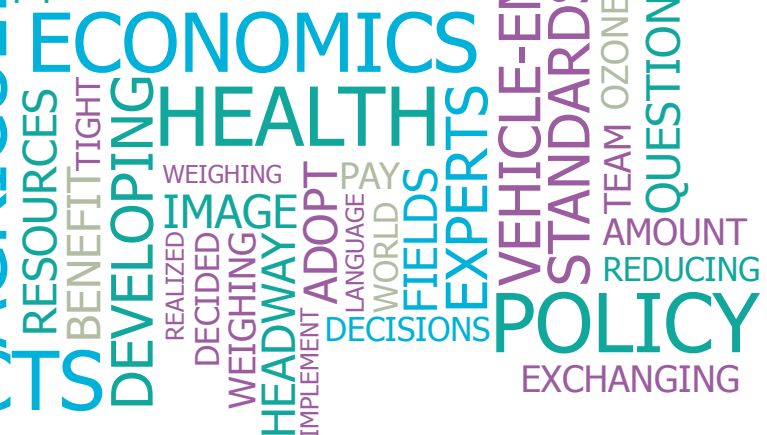

things - I was discussing aerosol optical thickness whereas my collaborator was talking about accumulated ozone over a threshold, which is a measure of ozone pollution.

\section{What was the highlight of working with an interdisciplinary team?}

This was the first time I had worked with such a diverse bunch of collaborators. What I found was that there was a small amount of additional complexity for a large amount of additional value. I was pleasantly surprised that we pulled the project off and managed to complete an end-to-end analysis. Furthermore, in trying to answer this particular question about the effects of implementing stringent vehicle-emission standards in developing countries, we found that you get a different perspective when you look at the issue collectively. For policy decisions, it's usually a matter of weighing one goal against another. However, quantifying a range of impacts is very important, because not all decision-makers have the same goals in mind - reducing climate-altering emissions might be a higher priority in developed countries, whereas protecting health and food supply are more important in developing countries. So each country might see a different primary benefit of having a policy that cuts emissions from vehicles.

\section{Did you learn any lessons about} interdisciplinary collaboration from this project that would benefit others trying to do similar work?

Check your units early on! Also, the question remains of how to pitch interdisciplinary work like this to funders. I had a grant proposal for this project rejected on the basis that although it was great for understanding societal impacts and understanding benefits, it didn't show enough new understanding of fundamental atmospheric science. So, I would advise people to think about who is going to pay for the research.

INTERVIEW BY OLIVE HEFFERNAN

This Beyond Boundaries is based on the work by Drew Shindell and colleagues, published on page 59 of this issue. 